\title{
A further cohort study of workers employed at a factory manufacturing chemicals for the rubber industry, with special reference to the chemicals 2-mercaptobenzothiazole (MBT), aniline, phenyl- $\beta$-naphthylamine and $o$-toluidine
}

Tom Sorahan, Linda Hamilton, John R Jackson

\begin{abstract}
Objectives-To investigate mortality and cancer morbidity in workers from a factory manufacturing chemicals for the rubber industry.

Methods-The mortality (1955-96) and cancer morbidity experience (1971-92) of a cohort of 2160 male production workers from a chemical factory in north Wales were investigated. All subjects had at least 6 months employment at the factory and some employment in the period 1955-84. Detailed job histories were abstracted from company computerised records and estimates of individual cumulative exposure to 2-mercaptobenzothiazole (MBT) and its derivatives were obtained, with a job exposure matrix derived by a former factory hygienist. Durations of employment in the aniline, phenyl- $\beta$-naphthylamine (PBN) and o-toluidine departments were also calculated. Two analytical approaches were used, indirect standardisation and Poisson regression.
\end{abstract}

Results-Based on serial rates for the general population of England and Wales, observed mortality for the total cohort was close to expectation for all causes (observed (obs) deaths 1131, expected (exp) deaths 1114.5, standardised mortality ratio (SMR) 101), and for all cancers (obs 305, exp 300.2, SMR 102). There was a significant $(p<0.05)$ excess mortality from cancer of the bladder in the 605 study subjects potentially exposed to one or more of the four chemicals being investigated (obs 9, exp 3.25 , SMR 277, 95\% confidence interval (95\% CI) 127 to 526). This excess was dependent primarily on deaths occurring $>20$ years after first exposure in those who started employment before 1955 (obs 7, exp 1.25, SMR 560, 95\% CI 225 to 1154 , $\mathbf{p}<0.001)$. There were 30 subjects in the total study cohort who, on the basis of death certificates or cancer registration particulars, had had malignant bladder cancer. In separate analyses of the four exposure history variables (after adjustment for age), Poisson regression showed significant positive trends for risk of notification of bladder cancer increasing with cumulative duration of employment in the PBN $(p<0.001)$ and $o$-toluidine departments $(p<0.01)$; similar findings were not obtained for cumulative exposure to MBT or for duration of employment in the aniline department. In a simultaneous analysis of all four chemical exposure variables, a significant positive trend remained for duration of employment with exposure to PBN $(p<0.05)$. Further analyses of all cases of bladder cancer (malignant and benign diagnoses) used employment histories lagged by 15 years; similar findings were obtained.

Conclusions-It seems likely that some members of this cohort have had occupational bladder cancer. Confident interpretation is difficult because of small numbers in the exposed subcohorts, relatively crude measures of exposure assessment for the four chemicals under study, and presence of unconsidered potential chemical confounders. The simplest interpretation of the findings about bladder cancer may be that PBN (or a chemical reagent or chemical intermediate associated with its production at this factory in the 1930s and 1940s) is a bladder carcinogen. Priority should be given, however, to obtaining information on the cancer experience of other working populations exposed to PBN or to o-toluidine.

(Occup Environ Med 2000;57:106-115)

Keywords: 2 -mercaptobenzothiazole; phenyl- $\beta$-naphthylamine; $o$-toluidine; aniline

A previous investigation studied the mortality of workers employed at a chemicals production factory in north Wales, which manufactures and uses vulcanisation inhibitors and accelerators, antioxidants, and many other proprietary products for the rubber industry. ${ }^{1}$ The study cohort comprised 2160 male production workers with a minimum period of employment of 6 months and some employment in the period 1955-84. Most of the cohort $(n=1549)$ started employment with the company before 1955 . Mortality was investigated to the end of 1986 and the overall experience of the cohort was close to expectation (based on national mortality rates), both for all cancers (standardised mortality ratio (SMR) 98, observed (obs) 215) and for all causes (SMR 100, obs 845). Given the multiple statistical tests carried out in the analysis, a striking aspect of the results was a lack of 
significance. None of the site specific SMRs for cancer mortality was significantly different from 100; this applied to the total study cohort and to four subcohorts with potential exposure to either (a) 2-mercaptobenzothiazole (MBT) and its derivatives, $(b)$ polymerised 2,2,4-trimethyl1,2-dihydroquinoline (TMQ), (c) phenyl- $\beta$ naphthylamine $(\mathrm{PBN})$, or (d) aniline or $o$-toluidine. However, only few site specific deaths were available for analysis of the subcohorts and confident interpretation was not possible. A non-significant excess of bladder cancer was found for the subcohort exposed to MBT (obs 3, exp 1.1, SMR 271).

Another epidemiological investigation reported on mortality trends for 1059 production workers at a United States rubber chemicals factory in Nitro, West Virginia. ${ }^{2}$ There was a marked excess of deaths from bladder cancer (obs 13, exp 1.63, SMR 797). Most or all of this excess could be attributed to exposure to p-aminobiphenyl (PAB), a known potent bladder carcinogen, ${ }^{3}$ and the United States study may not be able to provide reliable data on any independent effects of MBT exposure. Such information might be gained, however, by updating the United Kingdom study. There is now an additional 10 years of follow up data available for analysis. Also, a request was made to the Office for National Statistics (ONS) to provide cancer registration data as well as mortality data. No new hypotheses were generated from the previous findings from the United Kingdom study ${ }^{1}$; the original findings are subsumed, therefore, in revised overall findings for the period 1955-96. It follows that the two studies are not independent, rather that the second is an extension of the first. Any hypotheses generated from the new study findings would have to be tested in studies of other populations.

\section{Materials and methods}

MATERIALS

For the first analysis, the company supplied a computer tape comprising identifying particulars for all employees known to have worked at the factory in the period $1955-84 .^{1}$ This tape also included detailed coded job histories, but for hourly paid personnel only. Two subcohorts were identified; a survivor population in employment on 1 January 1955 and an entry cohort of employees who started work in the period 1955-84. Employees working <6
Table 1 Vital status at closing date of study (31 December 1996)

\begin{tabular}{lrr}
\hline Vital status & \multicolumn{2}{c}{$n$} \\
\hline Flagged alive at NHSCR & 889 & 41.2 \\
Traced alive, DSS ${ }^{\star}$ offices & 8 & 0.4 \\
Traced alive, company pensions & 20 & 0.9 \\
Died, cause knownt & 1185 & 54.9 \\
Died, cause not known & 12 & 0.6 \\
Emigrated & 14 & 0.6 \\
No trace & 32 & 1.5 \\
Total & 2160 & 100.0 \\
\hline
\end{tabular}

${ }^{\star}$ Department of Social Security, using National Insurance numbers.

†Includes deaths after 85

months were excluded and an initial data file contained information on 2340 hourly paid personnel and 382 salaried personnel. The classification of salaried and hourly staff referred to the most recent job carried out at the factory, and it was necessary to categorise personnel on the basis of first job at the factory. Job histories for all salaried personnel were sought, therefore, both from paper and microfilmed records stored in the company's personnel department. Several employees were found to have started employment at the factory as hourly paid staff and later transferred to salaried staff, and the final data file contained information on 2410 hourly paid personnel and 312 salaried personnel (based on first job). After excluding the 312 salaried personnel and 250 female hourly paid staff, 2160 male hourly paid staff remained (survivor population $(n=1549)$, entry cohort $(n=611))$. The updated analysis is based on the cohort of 2160 hourly paid staff; female employees were not engaged principally in production work.

Considerable use had been made of company personnel and pension records to trace study subjects for the first analysis ${ }^{1}$; arrangements have since been made to "flag" (trace) all employees at the National Health Service Central Register (NHSCR) both to simplify the tracing process for this analysis and to obtain cancer registration data. Vital status was determined for some $98 \%$ of the cohort (table 1).

\section{METHODS}

Exposure assessment

Job histories for the period 1930-84 were available as some 300 unique job-department titles, and these titles had been reviewed by a former occupational hygienist from the factory for likely exposures to the groups of chemicals already listed. For MBT and MBT derivatives,

Table 2 Estimated 8 hour TWA exposures ${ }^{*}$ to MBT and its derivative by job and department title and by calendar period

\begin{tabular}{|c|c|c|c|c|c|c|c|c|}
\hline \multirow[b]{2}{*}{ Department } & \multirow[b]{2}{*}{ Department code } & \multirow[b]{2}{*}{ fobs } & \multicolumn{6}{|c|}{ Applied to earlier periods } \\
\hline & & & $1955-60$ & $1961-67$ & $1968-77$ & $1978-80$ & $1981-81$ & $1982-85$ \\
\hline MBT solution & 82936 & Autoclave operator, dissolver bath operator, dayman & 1.75 & 1.75 & 1.75 & 0.50 & 0.50 & 0.50 \\
\hline Bantex or Thiotax & 99909 & Centrifuge mill operator & 4.25 & 4.25 & 4.25 & 1.75 & 1.75 & 1.75 \\
\hline$"$ & $”$ & Day bagging operator & 4.25 & 4.25 & 4.25 & 4.25 & 0.88 & 0.88 \\
\hline$"$ & ” & Packing or precipitator operator, flexible operator & 1.75 & 1.75 & 1.75 & 1.75 & 1.75 & 0.0 \\
\hline Pelleting & 99905 & Pellet operator & 0.0 & 11.70 & 11.70 & 3.83 & 3.83 & 1.75 \\
\hline & & Day pack operator & 0.0 & 11.70 & 11.70 & 2.33 & 2.33 & 1.75 \\
\hline Milling and blending & 99980 & Blending operator & 1.95 & 1.95 & 1.95 & 0.64 & 3.24 & 3.24 \\
\hline Thiofide & 82957 & Senior operator, flexible operator & 2.25 & 2.25 & 2.25 & 2.25 & 2.25 & 0.85 \\
\hline$"$ & $"$ & Bag flake operator, dayman & 8.50 & 8.50 & 6.00 & 6.00 & 6.00 & 0.85 \\
\hline Thiurams & 99970 & Filtrate pellet operator & 0.0 & 0.0 & 2.13 & 2.13 & 0.0 & 0.0 \\
\hline & $"$ & Dayman & 0.0 & 0.0 & 6.50 & 6.50 & 0.0 & 0.0 \\
\hline All others & - & - & 0.0 & 0.0 & 0.0 & 0.0 & 0.0 & 0.0 \\
\hline
\end{tabular}

*The precision suggested by two places of decimals is spurious and should be ignored. 
Table 3 Distribution of deaths (and bladder cancer notification) and person-years at risk, 1955-96

\begin{tabular}{|c|c|c|c|c|c|}
\hline Variable with levels & $\begin{array}{l}\text { Bladder cancer } \\
\text { deaths }{ }^{\star}\end{array}$ & $\begin{array}{l}\text { Bladder cancer } \\
\text { notifications } \\
\text { (malignant) } t\end{array}$ & $\begin{array}{l}\text { Bladder cancer } \\
\text { notifications (malignant } \\
\text { and benign) } \neq\end{array}$ & $\begin{array}{l}\text { All deaths } \\
\text { excluding } \\
\text { bladder cancer } \int\end{array}$ & Person-years at risk \\
\hline \multicolumn{6}{|l|}{ Age: } \\
\hline $15-19$ & 0 & 0 & 0 & 1 & 511.9 \\
\hline $20-29$ & 0 & 0 & 0 & 2 & 3985.7 \\
\hline $30-34$ & 0 & 0 & 0 & 5 & 3986.5 \\
\hline $35-39$ & 0 & 0 & 0 & 9 & 5191.6 \\
\hline $40-44$ & 0 & 0 & 0 & 15 & 6156.4 \\
\hline $45-49$ & 0 & 0 & 0 & 28 & 6914.3 \\
\hline $50-54$ & 1 & 1 & 1 & 52 & 7545.9 \\
\hline $55-59$ & 0 & 1 & 2 & 103 & 7587.4 \\
\hline $60-64$ & 0 & 5 & 6 & 150 & 6965.2 \\
\hline $65-69$ & 6 & 9 & 11 & 204 & 5585.8 \\
\hline $70-74$ & 10 & 7 & 15 & 242 & 3686.4 \\
\hline $75-79$ & 2 & 3 & 3 & 187 & 1957.3 \\
\hline $80-84$ & 3 & 4 & 3 & 111 & 895.8 \\
\hline \multicolumn{6}{|l|}{ Calendar year $\|:$} \\
\hline $1955-70$ & 1 & 1 & 1 & 289 & 27110.1 \\
\hline $1971-80$ & 5 & 6 & 16 & 325 & 15443.9 \\
\hline $1981-92$ & 12 & 21 & 22 & 396 & 14636.7 \\
\hline $1993-96$ & 4 & 2 & 2 & 99 & 3779.3 \\
\hline \multicolumn{6}{|c|}{ Year of starting employment: } \\
\hline$<1955^{\star \star}$ & 20 & 26 & 36 & 987 & 44238.4 \\
\hline $1955-84+\dagger$ & 2 & 4 & 5 & 122 & 16731.5 \\
\hline \multicolumn{6}{|l|}{ Employment status: } \\
\hline Still employed & 1 & 3 & 6 & 209 & 32165.8 \\
\hline Left employment†† & 21 & 27 & 35 & 900 & 28804.1 \\
\hline \multicolumn{6}{|c|}{ Period from first employment (y): } \\
\hline $0-9$ & 0 & 0 & 0 & 29 & 11125.9 \\
\hline $10-19$ & 0 & 1 & 2 & 142 & 17234.3 \\
\hline $20-29$ & 4 & 4 & 10 & 293 & 15511.1 \\
\hline$\geqslant 30$ & 18 & 25 & 29 & 645 & 17098.6 \\
\hline \multicolumn{6}{|c|}{ Cumulative exposure to MBT (mg.m $\left.\mathrm{m}^{-3} \cdot \mathrm{y}\right)$ : } \\
\hline None & 14 & 21 & 31 & 959 & 52646.4 \\
\hline $0.01-21.24$ & 4 & 5 & 5 & 83 & 5449.3 \\
\hline $21.25-63.74$ & 3 & 3 & 3 & 47 & 2081.8 \\
\hline$\geqslant 63.75$ & 1 & 1 & 2 & 20 & 792.4 \\
\hline \multicolumn{6}{|c|}{ Duration of employment in PBN department (y): } \\
\hline None & 18 & 25 & 35 & 1044 & 58755.9 \\
\hline $1-4$ & 0 & 1 & 2 & 38 & 1406.5 \\
\hline$\geqslant 5$ & 4 & 4 & 4 & 27 & 807.6 \\
\hline \multicolumn{6}{|c|}{ Duration of employment in aniline department (y): } \\
\hline None & 17 & 23 & 32 & 938 & 51375.7 \\
\hline $1-4$ & 1 & 2 & 4 & 101 & 5874.8 \\
\hline$\geqslant 5$ & 4 & 5 & 5 & 70 & 3719.4 \\
\hline \multicolumn{6}{|c|}{ Duration of employment in $o$-toluidine department $(\mathrm{y})$ : } \\
\hline None & 19 & 27 & 37 & 1095 & 59802.3 \\
\hline $1-4$ & 2 & 2 & 2 & 7 & 884.4 \\
\hline$\geqslant 5$ & 1 & 1 & 2 & 7 & 283.2 \\
\hline
\end{tabular}

*Any part of death certificate coded to ICD-8 188

†First notification of bladder cancer (ICD-8 188) from death certificate or from cancer registration particulars.

¥First notification of bladder cancer (malignant, benign, in situ, uncertain behaviour or unspecified nature (ICD-8: 188.0-188.9, 223.3, 237.6; ICD-9: 188.0-188.9, 223.3, 233.7, 236.7, 239.4)) from death certificate or from cancer registration particulars.

§Bladder cancer as defined in ${ }^{\star}$.

ๆBladder cancer registrations (incident cancers) not available for first and last period.

$\star \star$ Survivor population (see text).

††Entry cohort (see text).

$\ddagger \ddagger$ Subjects enter the person-years for this category 3 months after leaving employment.

estimates of 8 hour time weighted average exposures had been made for each job and department title and for several periods. Jobs attracted either zero exposure, very low exposure $\left(0-1 \quad \mathrm{mg} \cdot \mathrm{m}^{-3}\right)$, low exposure $(1-2.5$ $\mathrm{mg} \cdot \mathrm{m}^{-3}$, medium exposure $\left(2.5-6 \mathrm{mg} \cdot \mathrm{m}^{-3}\right)$, or high exposure $\left(6-20 \mathrm{mg} \cdot \mathrm{m}^{-3}\right)$. These estimates had been based on monitoring data for the period 1977 onwards, a review of the process manuals and other company records for earlier years, and discussions with long serving employees. Exposure estimates had then been adjusted by a "year fraction" factor to take into account the fact that some jobs were not associated with exposure to MBT throughout the whole of the working year-for example, product campaigns. For this analysis, midclass values of the adjusted exposure ranges were used as point estimates of exposure level. The final job exposure matrix is shown in table 2 .

Individual cumulative exposures to MBT or its derivatives (a time dependent variable) were estimated by the sum of the products of relevant durations of employment and relevant exposure concentrations (mg. $\left.\mathrm{m}^{-3} \cdot \mathrm{y}\right)$. Attempts to produce equivalent job exposure matrices for PBN and $o$-toluidine were unsuccessful but it has been possible to classify periods of employment in the aniline department separately from periods of employment in the $o$-toluidine department; cumulative durations of employment in the aniline, PBN and $o$-toluidine departments were also calculated as three time dependent variables.

\section{External standard: SMR approach}

Expected numbers of deaths were calculated from serial mortality rates for England and Wales applied to similarly defined arrays of person-years at risk (pyr) generated by the data. Workers entered the pyr at the end of the 6 months minimum period of employment, or 1 January 1955, whichever was the later date. They left the pyr on the closing date of the 
Table 4 Mortality from all causes among male production workers $(n=2160), 1955-96$

\begin{tabular}{|c|c|c|c|c|}
\hline Variable with levels & Obs & $\operatorname{Exp}$ & $S M R$ & $(95 \% C I)$ \\
\hline \multicolumn{5}{|l|}{ Age at death: } \\
\hline$<60$ & 216 & 242.4 & 89 & (78 to 102$)$ \\
\hline $60-69$ & 360 & 374.1 & 96 & (87 to 107$)$ \\
\hline $70-79$ & 441 & 383.4 & 115 & (105 to 126$)$ \\
\hline $80-84$ & 114 & 114.6 & 100 & (82 to 120$)$ \\
\hline \multicolumn{5}{|l|}{ Year of death: } \\
\hline 1955-65 & 137 & 180.9 & 76 & (64 to 90 ) \\
\hline $1966-75$ & 311 & 291.4 & 107 & (95 to 119 ) \\
\hline $1976-85$ & 366 & 335.7 & 109 & (98 to 121 ) \\
\hline $1986-96$ & 317 & 306.5 & 103 & (92 to 115 ) \\
\hline \multicolumn{5}{|c|}{ Period from first employment $(\mathrm{y})$ : } \\
\hline $0-9$ & 29 & 39.2 & 74 & (50 to 106$)$ \\
\hline $10-19$ & 142 & 157.4 & 90 & (76 to 106$)$ \\
\hline $20-29$ & 297 & 285.9 & 104 & (92 to 116 ) \\
\hline$\geqslant 30$ & 663 & 632.0 & 105 & (97 to 113 ) \\
\hline
\end{tabular}

study (31 December 1996), the date of death, the date of emigration, or date last known alive, whichever was the earliest date. For the occupationally exposed subcohorts, subjects entered the pyr at the end of the 6 months minimum period of employment, or 1 January 1955 , or the date first employed in an exposed job, whichever was the later date. Standardised mortality ratios (SMRs) were calculated as the ratio of observed deaths to expected deaths, expressed as a percentage (both numerator and denominator refer to underlying causes of death). These procedures were accomplished with the PERSONYEARS software. ${ }^{4}$ Significance tests were two tailed and no contributions were made to observed or expected numbers past the age of 85 . This censoring at 85 was applied for three reasons. Firstly, published mortality rates are only available for the open

Table 5 Mortality among male production workers ( $n=2160)$, 1955-96

\begin{tabular}{|c|c|c|c|c|c|}
\hline Cause of death & $I C D-8$ & Obs & Expt & $S M R$ & $(95 \% C I)$ \\
\hline \multicolumn{6}{|l|}{ Cancers: } \\
\hline Lip & 140 & 0 & 0.1 & 0 & - \\
\hline Tongue & 141 & 0 & 0.9 & 0 & - \\
\hline Salivary gland & 142 & 0 & 0.4 & 0 & - \\
\hline Mouth & $143-5$ & 3 & 0.9 & 337 & (69 to 984$)$ \\
\hline Pharynx & $146-9$ & 2 & 1.9 & 107 & (13 to 385 ) \\
\hline Oesophagus & 150 & 11 & 9.8 & 113 & (50 to 202$)$ \\
\hline Stomach & 151 & 39 & 29.5 & 132 & (94 to 181 ) \\
\hline Small intestine & 152 & 0 & 0.5 & 0 & - \\
\hline Large intestine & 153 & 21 & 19.0 & 110 & (68 to 169 ) \\
\hline Rectum & 154 & 15 & 13.4 & 112 & (63 to 185 ) \\
\hline Liver & 155 & 1 & 2.0 & 51 & ( 1 to 285 ) \\
\hline Pancreas & 157 & 16 & 12.4 & 130 & (74 to 210$)$ \\
\hline Peritoneum & 158 & 0 & 0.5 & 0 & - \\
\hline Other digestive organs & 159 & 1 & 0.9 & 102 & (3 to 598 ) \\
\hline Nose and sinuses & 160 & 1 & 0.5 & 189 & ( 5 to 1054 ) \\
\hline Larynx & 161 & 4 & 2.9 & 141 & (38 to 360 ) \\
\hline Lung and bronchus & $162-3$ & 102 & 117.4 & 87 & (71 to 105 ) \\
\hline Bone & 170 & 1 & 0.6 & 157 & ( 4 to 877 ) \\
\hline Skin & $172-3$ & 2 & 2.4 & 84 & (10 to 303$)$ \\
\hline Breast & 174 & 0 & 0.4 & 0 & - \\
\hline Prostate & 185 & 15 & 20.6 & 73 & (41 to 120 ) \\
\hline Testis & 186 & 0 & 0.6 & 0 & - \\
\hline Other genital organs & 187 & 1 & 0.4 & 232 & (6 to 1292$)$ \\
\hline Bladder & 188 & 17 & 12.1 & 141 & (82 to 225$)$ \\
\hline Other urinary organs & 189 & 4 & 5.3 & 76 & ( 21 to 194$)$ \\
\hline Brain & $191-2$ & 7 & 5.8 & 121 & (49 to 249 ) \\
\hline Thyroid & 193 & 0 & 0.5 & 0 & - \\
\hline Hodgkin's disease & 201 & 1 & 1.6 & 61 & ( 2 to 340 ) \\
\hline Lymphosarcoma & 200,202 & 4 & 5.3 & 76 & (21 to 194$)$ \\
\hline Multiple myeloma & 203 & 2 & 3.4 & 60 & ( 7 to 216 ) \\
\hline Leukaemia & $204-7$ & 7 & 6.6 & 106 & (42 to 218$)$ \\
\hline All neoplasms & $140-239$ & 305 & 300.2 & 102 & (91 to 114 ) \\
\hline \multicolumn{6}{|l|}{ Non-cancers: } \\
\hline Diseases of circulatory system & $390-458$ & 543 & 542.7 & 100 & (92 to 109$)$ \\
\hline Diseases of respiratory system & $460-519$ & 166 & 144.7 & 115 & (98 to 134 ) \\
\hline Accidents & $800-949$ & $13(\star)$ & 23.0 & 56 & ( 30 to 97 ) \\
\hline Suicide & $950-959$ & 6 & 10.2 & 59 & ( 22 to 128$)$ \\
\hline All causes & & 1131 & 1114.5 & 101 & (96 to 108 ) \\
\hline
\end{tabular}

${ }^{\star} \mathrm{p}<0.05,()$ indicates deficit.

†Expectations based on serial mortality rates for England and Wales. ended age group $\geqslant 85$ and the distribution of the cohort pyr by single years of age might be very different from that of the general population; secondly, the reliability of cause of death particulars is probably poorer at later ages, and thirdly, any study subjects incorrectly classified as traced alive at the end of the study would have a disproportionate effect on the expected numbers for the open ended age group.

Equivalent analyses were carried out for cancer registration (incidence) data. National cancer registration data are not available before 1971, and the calculation of standardised registration ratios (SRRs) was limited to the period 1971-92. Incident cases diagnosed later than 1992 could not be identified because there is a delay in the national registration of cancer diagnoses.

Internal standard: Poisson regression

The SMR analysis had to be limited to an analysis of underlying causes of death. For the internal analysis greater flexibility was available and cases of bladder cancer were selected as those deaths for which primary cancer of the bladder was mentioned on any part of the death certificate. This approach introduced a further five cases of bladder cancer not available to the SMR analyses. Exposures to the chemicals under investigation were not expected to have a discernible influence on many causes of death. Consequently, mortality from all causes excluding bladder cancer (as already defined) was also studied to assess the usefulness of the explanatory variables used in the statistical models.

Several variables were considered to have the potential for influencing mortality within the cohort: age, year of start of employment, calendar period, period from first employment, employment status (still employed or left employment), cumulative exposure to MBT, and duration of employment in the aniline, PBN, or $o$-toluidine departments. Variables were not treated as continuous variables, but rather each variable was categorised into several levels. In constructing the models, it was necessary to ensure that there was at least one death observed at each level of each variable. Any adjustments were made before any statistical modelling was carried out; the initial categories are shown in table 3. Most of these variables are time dependent and the analysis allows subjects to contribute pyr to contemporaneous categories. There were no cases of bladder cancer at very young ages; most analyses were limited, therefore, to the age range $40-84$ years (the expected number of bladder cancer deaths at age $<40$ was only 0.02 , based on national mortality rates).

The statistical power of the analysis of risks of bladder cancer was increased by carrying out further analyses of two sets of notifications about bladder cancer. Cases of malignant bladder cancer were notified by death certificate only (nine cases), by cancer registration particulars only (eight cases), or by both sources (13 cases). Cases of bladder tumours (malignant or benign) were notified by death certificate only (seven cases), by cancer regis- 
Table 6 Cancer registrations (incident cancers) among male production workers ( $n=$ 1801†), 1971-92

\begin{tabular}{|c|c|c|c|c|c|}
\hline Site of cancer & $I C D-8$ & $O b s$ & $\operatorname{Exp} \ddagger$ & $S R R$ & $(95 \% C I)$ \\
\hline Lip & 140 & 0 & 0.7 & 0 & - \\
\hline Tongue & 141 & 0 & 0.9 & 0 & - \\
\hline Salivary gland & 142 & 1 & 0.5 & 200 & ( 5 to 1114 ) \\
\hline Mouth & $143-5$ & 3 & 1.2 & 250 & (52 to 731 ) \\
\hline Pharynx & $146-9$ & 2 & 1.7 & 118 & (14 to 425$)$ \\
\hline Oesophagus & 150 & 7 & 6.3 & 111 & (45 to 229 ) \\
\hline Stomach & 151 & 24 & 18.7 & 128 & (82 to 191 ) \\
\hline Small intestine & 152 & 0 & 0.5 & 0 & - \\
\hline Large intestine & 153 & 18 & 16.8 & 107 & (63 to 169 ) \\
\hline Rectum & 154 & 17 & 13.6 & 125 & (73 to 200 ) \\
\hline Liver & 155 & 4 & 1.5 & 267 & (73 to 683 ) \\
\hline Gall bladder & 156 & 1 & 1.3 & 77 & $(2$ to 429$)$ \\
\hline Pancreas & 157 & 9 & 7.7 & 117 & (53 to 222 ) \\
\hline Peritoneum and other digestive & $158-9$ & 1 & 0.7 & 143 & ( 4 to 796$)$ \\
\hline Nose and sinuses & 160 & 0 & 0.6 & 0 & - \\
\hline Larynx & 161 & 3 & 4.1 & 73 & (15 to 214 ) \\
\hline Lung and bronchus & $162-3$ & 65 & 74.4 & 87 & ( 67 to 111 ) \\
\hline Bone & 170 & 1 & 0.4 & 250 & (6 to 1393 ) \\
\hline Connective tissue & 171 & 0 & 1.0 & 0 & - \\
\hline Malignant melanoma & 172 & 0 & 1.8 & 0 & - \\
\hline Breast & 174 & 1 & 0.5 & 200 & ( 5 to 1114 ) \\
\hline Prostate & 185 & $12\left(^{\star}\right)$ & 23.3 & 52 & (27 to 90 ) \\
\hline Testis & 186 & 0 & 1.0 & 0 & - \\
\hline Other genital & 187 & 2 & 0.8 & 250 & (30 to 903 ) \\
\hline Bladder & 188 & 19 & 17.7 & 107 & (65 to 168 ) \\
\hline Other urinary & 189 & 9 & 4.9 & 184 & (84 to 349 ) \\
\hline Eye & 190 & 0 & 0.4 & 0 & - \\
\hline Brain & $191-2$ & 4 & 3.5 & 114 & (31 to 293 ) \\
\hline Thyroid & 193 & 0 & 0.5 & 0 & - \\
\hline Other endocrine & 194 & 0 & 0.2 & 0 & - \\
\hline Secondary and other & $195-9$ & 19 & 12.1 & 157 & (95 to 245 ) \\
\hline Hodgkin's disease & 201 & 0 & 1.2 & 0 & - \\
\hline Lymphosarcoma & 200,202 & 2 & 5.1 & 39 & (5 to 142 ) \\
\hline Multiple myeloma & 203 & 4 & 2.8 & 143 & (39 to 366 ) \\
\hline Leukaemia & $204-7$ & 5 & 5.1 & 98 & (32 to 229 ) \\
\hline All cancers $\rrbracket$ & $140-207$ & 234 & 233.6 & 100 & (88 to 114 ) \\
\hline
\end{tabular}

${ }^{\star} \mathrm{p}<0.05,($ ) indicates deficit.

†Analysis excludes study subjects not flagged at NHSCR, and study subjects who emigrated or died before 1971.

$\ddagger$ Based on serial cancer registration rates for England and Wales, 1971-88.

$§$ Excluding non-melatonous skin cancer (ICD-8 173).

tration particulars only (18 cases), or by both sources (16 cases). For such analyses, case subjects leave the pyr on the date of the first notification. Consequently, the number of bladder cancer notifications in a single age group can be fewer than the number of bladder cancer deaths in that age group (this does not apply, of course, to cumulative numbers). The distributions of notifications of bladder cancer relative to the explanatory variables are also shown in table 3.

The EPICURE computer program was used to provide pyr and numbers of deaths for all combinations of all levels of the selected variables. ${ }^{5}$ The EPICURE program was also used to carry out statistical modelling by Poisson regression. ${ }^{6}$ The purpose of the modelling was to calculate point estimates of relative risk (rate ratios) for each level of the four occupational exposure variables, with and without adjustment for other variables. The significance of any trend in risk across the four cumulative MBT exposure categories was assessed by repeating the analysis while treating cumulative exposure as a continuous variable, coded 1, 2, 3, or 4 for the four levels of exposure. The cut off values for cumulative exposure to MBT were those used previously $\left(21.25 \text { and } 63.75 \mathrm{mg} \cdot \mathrm{m}^{-3} . \mathrm{y}\right)^{1}$; they had been selected to represent exposures equivalent to those received after 5 and 15 years in jobs with medium exposure. Trends in risk across categories of duration of employment were evaluated in a similar manner.

\section{Results}

EXTERNAL STANDARD

Table 4 shows observed and expected numbers of deaths from all causes by age at death, by year of death, and by period from first employment. The findings by age at death and by year of death do not provide convincing evidence of inadequate tracing of deaths (classifying some dead people as alive at the end of the study period would lead to spuriously low SMRs at later ages and later periods of follow up). The positive trend of SMRs with period from first employment was consistent with the presence of a healthy worker effect.

Table 5 shows observed and expected numbers of deaths by site of cancer and by broad non-cancer groupings for all male production workers. The only significant difference between observed and expected numbers related to a deficit of deaths from accidents (obs 13, exp 23.0, SMR 56). A similarly low SMR was also found for suicide (obs 6, exp 10.2, SMR 59). There was a non-significant excess for cancer of the stomach (obs 39, exp 29.5, SMR 132) and a non-significant deficit for cancer of the lung (obs 102, exp 117.4, SMR 87). These findings were in keeping with local rates (county SMR 141 for cancer of the stomach; county SMR 84 for cancer of the lung). ${ }^{7}$ There was a non-significant excess for cancer of the bladder (obs 17, exp 12.1, SMR 141); this excess was not in keeping with local rates (county SMR 87). ${ }^{\text {? }}$

Table 6 shows observed and expected numbers of cancer registrations (incident cancers) by site of cancer for all male production workers. Registrations for all cancers were close to expectation (obs 234, exp 233.6, SRR 100). The only significant difference between observed and expected numbers related to a deficit of registrations for cancer of the prostate (obs 12, exp 23.3, SRR 52). Registrations for cancer of the bladder were close to expectation (obs 19, exp 17.7, SRR 107).

Table 7 shows observed and expected numbers of deaths by site of cancer and by broad non-cancer groupings for the subcohorts with potential exposure to the four chemicals of interest. Significant excesses were shown for cancer of the bladder among workers exposed to MBT (obs 7, exp 1.72), workers employed in the PBN department (obs 4, exp 0.62), and workers employed in the $o$-toluidine department (obs 3, exp 0.19). A significant excess was also shown for cancer of the large intestine among workers exposed to MBT (obs 7, exp 2.73). A non-significant excess was shown for cancer of the bladder among workers employed in the aniline department (obs 4, exp 2.00). There was considerable overlap in the membership of these subcohorts; and for the 605 workers with potential exposure to one or more of the four chemicals of interest, the SMR for bladder cancer was 277 (obs 9, exp 3.25, 95\% confidence interval (95\% CI) 127 to $526, \mathrm{p}<0.05$ ). (The corresponding SRR for registrations of malignant bladder tumours was 208 (obs 11, exp 5.3, 95\% CI 104 to 371 , $\mathrm{p}<0.05)$ ). The excess mortality was dependent on findings for those workers first exposed 
Table 7 Mortality among workers potentially exposed to 2-mercaptobenzothiazole (MBT) and its derivatives ( $n=357$ men), workers employed in the phenyl- $\beta$-napthylamine $(P B N)$ plant $(n=94$ men), workers employed in the aniline department $(n=385$ men), and workers employed in the o-toluidine department ( $n=53$ men), $1955-96$

\begin{tabular}{|c|c|c|c|c|c|c|c|c|c|c|c|c|c|}
\hline \multirow[b]{2}{*}{ Cause of death } & \multirow[b]{2}{*}{$I C D-8$} & \multicolumn{3}{|l|}{$M B T$} & \multicolumn{3}{|l|}{$P B N$} & \multicolumn{3}{|c|}{ Aniline } & \multicolumn{3}{|c|}{ o-Toluidine } \\
\hline & & $\mathrm{Obs}$ & $\operatorname{Exp}$ & $S M R$ & $\mathrm{Obs}$ & $\operatorname{Exp}$ & $S M R$ & $\mathrm{Obs}$ & $\operatorname{Exp}$ & $S M R$ & Obs & $\operatorname{Exp}$ & $S M R$ \\
\hline \multicolumn{14}{|l|}{ Cancers: } \\
\hline Buccal cavity throat & $140-9$ & 0 & 0.6 & 0 & 0 & 0.1 & 0 & 0 & 0.8 & 0 & 0 & 0.0 & 0 \\
\hline Oesophagus & 150 & 3 & 1.5 & 205 & 1 & 0.5 & 204 & 0 & 1.7 & 0 & 0 & 0.2 & 0 \\
\hline Stomach & 151 & 4 & 4.0 & 100 & 4 & 1.5 & 264 & 6 & 4.7 & 129 & 2 & 0.4 & 487 \\
\hline Small intestine & 152 & 0 & 0.1 & 0 & 0 & 0.0 & 0 & 0 & 0.1 & 0 & 0 & 0.0 & 0 \\
\hline Large intestine & 153 & $7^{\star}$ & 2.7 & 257 & 2 & 1.0 & 210 & 3 & 3.2 & 94 & 0 & 0.3 & 0 \\
\hline Rectum & 154 & 3 & 1.9 & 161 & 2 & 0.7 & 299 & 3 & 2.2 & 138 & 0 & 0.2 & 0 \\
\hline Liver & 155 & 0 & 0.3 & 0 & 0 & 0.1 & 0 & 0 & 0.4 & 0 & 0 & 0.1 & 0 \\
\hline Pancreas & 157 & 1 & 1.8 & 56 & 1 & 0.6 & 158 & 2 & 2.1 & 97 & 0 & 0.2 & 0 \\
\hline Other digestive organs & $158-9$ & 0 & 0.3 & 0 & 0 & 0.1 & 0 & 0 & 0.3 & 0 & 0 & 0.0 & 0 \\
\hline Nose and sinuses & 160 & 0 & 0.1 & 0 & 0 & 0.0 & 0 & 0 & 0.1 & 0 & 0 & 0.0 & 0 \\
\hline Larynx & 161 & 0 & 0.4 & 0 & 0 & 0.1 & 0 & 1 & 0.5 & 217 & 0 & 0.1 & 0 \\
\hline Lung and bronchus & $162-3$ & 15 & 16.7 & 90 & 5 & 6.2 & 81 & 16 & 19.4 & 83 & 1 & 1.9 & 52 \\
\hline Bone & 170 & 0 & 0.1 & 0 & 0 & 0.0 & 0 & 0 & 0.1 & 0 & 0 & 0.0 & 0 \\
\hline Skin & $172-3$ & 1 & 0.4 & 282 & 0 & 0.1 & 0 & 1 & 0.4 & 244 & 0 & 0.1 & 0 \\
\hline Breast & 174 & 0 & 0.1 & 0 & 0 & 0.0 & 0 & 0 & 0.1 & 0 & 0 & 0.0 & 0 \\
\hline Prostate & 185 & 0 & 3.0 & 0 & 0 & 1.1 & 0 & 0 & 3.6 & 0 & 0 & 0.3 & 0 \\
\hline Testis & 186 & 0 & 0.1 & 0 & 0 & 0.0 & 0 & 0 & 0.1 & 0 & 0 & 0.0 & 0 \\
\hline Other genital organs & 187 & 0 & 0.1 & 0 & 0 & 0.0 & 0 & 0 & 0.1 & 0 & 0 & 0.0 & 0 \\
\hline Bladder & 188 & $7 \star \star$ & 1.7 & 408 & $4^{\star \star}$ & 0.6 & 641 & 4 & 2.0 & 200 & $3 \star \star$ & 0.2 & 1589 \\
\hline Other urinary organs & 189 & 2 & 0.8 & 254 & 1 & 0.3 & 383 & 3 & 0.9 & 329 & 1 & 0.1 & 947 \\
\hline Brain & $191-2$ & 3 & 0.9 & 351 & 0 & 0.3 & 0 & 1 & 1.0 & 102 & 0 & 0.1 & 0 \\
\hline Thyroid & 193 & 0 & 0.1 & 0 & 0 & 0.0 & 0 & 0 & 0.1 & 0 & 0 & 0.0 & 0 \\
\hline Lymphomas & $200-3$ & 1 & 1.3 & 77 & 0 & 0.6 & 0 & 1 & 1.7 & 59 & 0 & 0.2 & 0 \\
\hline Leukaemia & $204-7$ & 3 & 1.0 & 317 & 0 & 0.3 & 0 & 2 & 1.1 & 182 & 0 & 0.1 & 0 \\
\hline All neoplasms & $140-239$ & 52 & 43.1 & 121 & 21 & 15.3 & 137 & 48 & 50.0 & 96 & 7 & 5.1 & 137 \\
\hline \multicolumn{14}{|l|}{ Non-cancers: } \\
\hline Diseases of circulatory system & $390-458$ & 67 & 75.5 & 89 & 31 & 27.5 & 113 & 83 & 88.1 & 94 & 4 & 8.2 & 49 \\
\hline Diseases of respiratory system & $460-519$ & 20 & 18.9 & 106 & 11 & 7.2 & 153 & 25 & 22.2 & 113 & 4 & 1.7 & 239 \\
\hline Accidents & $800-949$ & 2 & 2.9 & 68 & 0 & 0.9 & 0 & 2 & 3.5 & 58 & 1 & 0.3 & 290 \\
\hline Suicide & $950-959$ & 1 & 1.4 & 73 & 0 & 0.4 & 0 & 1 & 1.6 & 63 & 0 & 0.2 & 0 \\
\hline All causes & & 158 & 154.7 & 102 & 69 & 55.8 & 124 & 176 & 180.6 & 97 & 17 & 16.9 & 100 \\
\hline
\end{tabular}

${ }^{\star} \mathrm{p}<0.05 ;{ }^{\star \star} \mathrm{p}<0.01$.

Table 8 Relative risks of mortality from bladder cancer and all causes excluding bladder cancer by potential exposure to various chemicals, employment histories are unlagged

\begin{tabular}{|c|c|c|c|c|}
\hline \multirow[b]{2}{*}{ Variable with levels } & \multicolumn{2}{|c|}{ Bladder cancert } & \multicolumn{2}{|c|}{ All other causes } \\
\hline & $n$ & $\begin{array}{l}R R(95 \% C I) \\
\text { simultaneous } \\
\text { analysis } \neq\end{array}$ & $n$ & $\begin{array}{l}R R(95 \% C I) \\
\text { simultaneous analysis } \neq\end{array}$ \\
\hline \multicolumn{5}{|c|}{ Cumulative exposure to MBT $\left(\mathrm{mg} \cdot \mu^{-3} \mathrm{y}\right)$ : } \\
\hline None & 14 & 1.0 & 959 & 1.0 \\
\hline $0.01-21.24$ & 4 & $2.69(0.77$ to 9.48$)$ & 83 & $1.06(0.84$ to 1.34$)$ \\
\hline $21.25-63.74$ & 3 & 2.69 (0.68 to 10.58$)$ & 47 & $0.94(0.69$ to 1.28$)$ \\
\hline$\geqslant 63.75$ & 1 & $2.10(0.27$ to 16.43$)$ & 20 & $0.79(0.51$ to 1.24$)$ \\
\hline $\mathrm{p}$ Value for trend $\Omega$ & & $\mathrm{p}=0.24$ & & $\mathrm{p}=0.43$ \\
\hline \multicolumn{5}{|c|}{ Duration of employment in PBN department (y): } \\
\hline None & 18 & 1.0 & 1044 & 1.0 \\
\hline $1-4$ & 0 & $1.75(0.42$ to 7.35$)$ & 38 & $1.23(0.88$ to 1.73$)$ \\
\hline$\geqslant 5$ & 4 & $1.15(0.42$ (0 7.53$)$ & 27 & $1.27(0.85$ to 1.88$)$ \\
\hline $\mathrm{p}$ Value for trend $\Omega$ & & $\mathrm{p}=0.048$ & & $\mathrm{p}=0.09$ \\
\hline \multicolumn{5}{|c|}{ Duration of employment in aniline department $(y)$ : } \\
\hline None & 17 & 1.0 & 938 & 1.0 \\
\hline $1-4$ & 1 & $0.34(0.04$ to 2.73$)$ & 101 & $1.04(0.84$ to 1.29$)$ \\
\hline$\geqslant 5$ & 4 & $1.31(0.39$ to 4.39$)$ & 70 & $0.79(0.61$ to 1.02$)$ \\
\hline $\mathrm{p}$ Value for trend $\sqrt{ }$ & & $\mathrm{p}>0.50$ & & $\mathrm{p}=0.15$ \\
\hline \multicolumn{5}{|c|}{ Duration of employment in $o$-toluidine department $(\mathrm{y})$ : } \\
\hline None & 19 & 1.0 & 1095 & 1.0 \\
\hline $1-4$ & 2 & 4.44 (0.76 to 25.79 & 7 & $0.48(0.22$ to 1.02$)$ \\
\hline$\geqslant 5$ & 1 & $5.48(0.51$ to 59.14$)$ & 7 & $1.23(0.57$ to 2.65$)$ \\
\hline $\mathrm{p}$ Value for trend $\varsigma$ & & $\mathrm{p}=0.08$ & & $\mathrm{p}>0.50$ \\
\hline
\end{tabular}

${ }^{\star} \mathrm{p}<0.05$.

†Any part of death certificate coded to ICD-8 188 (table 3, first column).

$\ddagger$ Column summarises a single analysis in which the four chemical exposure variables are analysed simultaneously with age.

§See text.
INTERNAL STANDARD

Table 8 provides relative risks of mortality from cancer of the bladder and mortality from all other causes by categories of cumulative exposure to MBT and its derivatives and by duration of employment in the PBN, aniline, and $o$-toluidine departments. Risks are all shown relative to a baseline risk of unity for workers (person-years) in the lowest exposure category for each variable. The two sets of columns in table 8 summarise the results of two analyses in which the four variables of employment history are analysed simultaneously with attained age. Consequently table 8 seeks to identify the independent effects of each of the four employment variables. Numbers of deaths from bladder cancer in all exposed categories are small but a significant positive trend is shown between risk of cancer and duration of employment in the PBN department. The corresponding finding for $o$-toluidine also approached formal levels of significance. Relative risks for all causes of death other than bladder cancer are close to unity. (The analyses summarised in table 8 were repeated with an alternative treatment of the MBT job exposure matrix. This time, the geometric means of the limits of the exposure ranges were used as the point estimates of exposure concentrations. The relative risks of $2.69,2.69$, and 2.10 shown in table 8 for risks of bladder cancer mortality relative to cumulative exposure to MBT were revised to $2.52,2.79$, and 2.30 , respectively. No further use is made of this alternative approach.)

Table 9 provides relative risks of all notifications of malignant neoplasms of the bladder by independent effects of exposures to these four chemicals. before 1955 (obs 7, exp 1.52, SMR 462, 95\% to $951, \mathrm{p}<0.01)$, and among th exposure (obs 7, exp 1.25, SMR 560, 95\% CI 225 to $1154, \mathrm{p}<0.001)$. Clearly, analyses are required which seek evidence of the possible 
Table 9 Relative risk of bladder cancer (all notifications of malignant neoplasmst) by potential exposure to various chemicals: employment histories are unlagged

\begin{tabular}{|c|c|c|c|c|c|}
\hline Variable with levels & $n$ & \multicolumn{2}{|c|}{$\begin{array}{l}R R(95 \% C I) \text { separate } \\
\text { analysis } \neq\end{array}$} & \multicolumn{2}{|c|}{$\begin{array}{l}\text { RR }(95 \% \text { CI) simultaneous } \\
\text { analysis } \widehat{S}\end{array}$} \\
\hline \multicolumn{6}{|c|}{ Cumulative exposure to MBT (mg. $\left.\mu^{-3} \mathrm{y}\right)$ : } \\
\hline None & 21 & 1.0 & & 1.0 & \\
\hline $0.01-21.24$ & 5 & $2.96^{\star}$ & (1.11 to 7.86$)$ & 2.24 & $(0.76$ to 6.60$)$ \\
\hline $21.25-63.74$ & 3 & 2.50 & (0.74 to 8.38$)$ & 1.46 & (0.38 to 5.63$)$ \\
\hline$\geqslant 63.75$ & 1 & 1.72 & (0.23 to 12.82$)$ & 1.21 & (0.15 to 9.54$)$ \\
\hline $\mathrm{p}$ Value for trend $\Phi$ & & $\mathrm{p}=0.06$ & & $\mathrm{p}=0.48$ & \\
\hline \multicolumn{6}{|c|}{ Duration of employment in PBN department (y): } \\
\hline None & 25 & 1.0 & & 1.0 & \\
\hline $1-4$ & 1 & 1.26 & (0.17 to 9.32$)$ & 0.58 & (0.06 to 5.46$)$ \\
\hline$\geqslant 5$ & 4 & $7.48^{\star \star}$ & (2.60 to 21.52$)$ & $4.35^{\star}$ & $(1.30$ to 14.57$)$ \\
\hline p Value for trend & & $\mathrm{p}<0.001$ & & $p=0.03$ & \\
\hline \multicolumn{6}{|c|}{ Duration of employment in aniline department (y): } \\
\hline None & 23 & 1.0 & & 1.0 & \\
\hline $1-4$ & 2 & 0.85 & (0.20 to 3.61$)$ & 0.61 & (0.14 to 2.76$)$ \\
\hline$\geqslant 5$ & 5 & 2.20 & (0.84 to 5.79$)$ & 1.50 & $(0.52$ to 4.35$)$ \\
\hline $\mathrm{p}$ Value for trend $\Phi$ & & $\mathrm{p}=0.17$ & & $\mathrm{p}>0.50$ & \\
\hline \multicolumn{6}{|c|}{ Duration of employment in $o$-toluidine department (y): } \\
\hline None & 27 & 1.0 & & 1.0 & \\
\hline $1-4$ & 2 & $6.73^{\star}$ & (1.59 to 28.41$)$ & $5.18^{\star}$ & (1.04 to 25.80$)$ \\
\hline & 1 & $7.65^{\star}$ & (1.03 to 56.87 ) & 2.73 & (0.29 to 25.45$)$ \\
\hline $\mathrm{p}$ Value for trend $\uparrow$ & & $\mathrm{p}=0.002$ & & $\mathrm{p}=0.31$ & \\
\hline
\end{tabular}

${ }^{\star} \mathrm{p}<0.05 ;{ }^{\star \star} \mathrm{p}<0.01 ;{ }^{\star \star \star} \mathrm{p}<0.001$.

†See table 3, second column.

$\ddagger$ Column summarises four analyses, only adjusting for age.

¿Column summarises a single analysis in which the four chemical exposure variables are analysed simultaneously with age.

ISee text.

concentrations of the four variables of interest. The first set of columns summarises four separate analyses in which each employment history variable is analysed in turn with only simultaneous adjustment for age. The second set of columns summarises a single analysis in which the four chemical exposures are analysed together with simultaneous adjustment for age (as in table 8). Significant positive trends are shown for PBN and $o$-toluidine when exposures are analysed separately. All point estimates of risk are somewhat reduced when the four exposures are analysed simultaneously, although a significant positive trend (not monotonic) is still shown for PBN. A further single analysis with additional adjustment for

Table 10 Relative risk of bladder cancer (all notifications of malignant and benign neoplasmst) by potential exposure to various chemicals; employment histories are lagged by 15 years

\begin{tabular}{|c|c|c|c|}
\hline Variable with levels & $n$ & $\begin{array}{l}R R(95 \% C I) \text { separate } \\
\text { analysis } \neq\end{array}$ & $\begin{array}{l}\text { RR (95\% CI) simultaneous } \\
\text { analysis } \int\end{array}$ \\
\hline \multicolumn{4}{|c|}{ Cumulative exposure to MBT (mg. $\left.\mu^{-3} \mathrm{y}\right)$ : } \\
\hline None & 34 & 1.0 & 1.0 \\
\hline $0.01-21.24$ & 3 & $1.40(0.43$ to 4.54$)$ & $1.18(0.34$ to 4.07$)$ \\
\hline $21.25-63.74$ & 4 & $2.16(0.76$ to 6.12$)$ & $1.84(0.58$ to 5.86$)$ \\
\hline $\begin{array}{l}\geqslant 63.75 \\
\mathrm{p} \text { Value for trend }\end{array}$ & 0 & $\mathrm{p}=0.23$ & $\mathrm{p}=0.49$ \\
\hline \multicolumn{4}{|c|}{ Duration of employment in PBN department (y): } \\
\hline None & 36 & 1.0 & 1.0 \\
\hline $1-4$ & 2 & $2.01(0.48$ to 8.36$)$ & $1.46(0.31$ to 6.95$)$ \\
\hline$\geqslant 5$ & 3 & $4.73^{\star}(1.45$ to 15.42$)$ & $3.48(0.98$ to 12.40$)$ \\
\hline $\mathrm{p}$ Value for trend & & $\mathrm{p}=0.007$ & $\mathrm{p}=0.059$ \\
\hline \multicolumn{4}{|c|}{ Duration of employment in aniline department $(y)$ : } \\
\hline None & 35 & 1.0 & 1.0 \\
\hline $1-4$ & 3 & $1.03(0.32$ to 3.34$)$ & $0.86(0.25$ to 2.90$)$ \\
\hline$\geqslant 5$ & 3 & $1.23(0.38$ to 4.01$)$ & $0.94(0.26$ to 3.37$)$ \\
\hline p Value for trend $q$ & & $\mathrm{p}>0.50$ & $\mathrm{p}>0.50$ \\
\hline \multicolumn{4}{|c|}{ Duration of employment in $o$-toluidine department $(\mathrm{y})$ : } \\
\hline None & 39 & 1.0 & 1.0 \\
\hline $1-4$ & 1 & $3.11(0.43$ to 22.65$)$ & $2.05(0.24$ to 17.28$)$ \\
\hline$\geqslant 5$ & 1 & $13.43^{\star}(1.84$ to 98.06$)$ & $7.64(0.90$ to 65.14$)$ \\
\hline $\mathrm{p}$ Value for trend $\boldsymbol{\Psi}$ & & $\mathrm{p}=0.007$ & $\mathrm{p}=0.076$ \\
\hline
\end{tabular}

${ }^{\star} \mathrm{p}<0.05,{ }^{\star \star} \mathrm{p}<0.01$.

†See table 3, third column

$\ddagger$ Column summarises four analyses, only adjusting for age.

CColumn summarises a single analysis in which the four chemical exposure variables are analysed simultaneously with age.

qSee text.

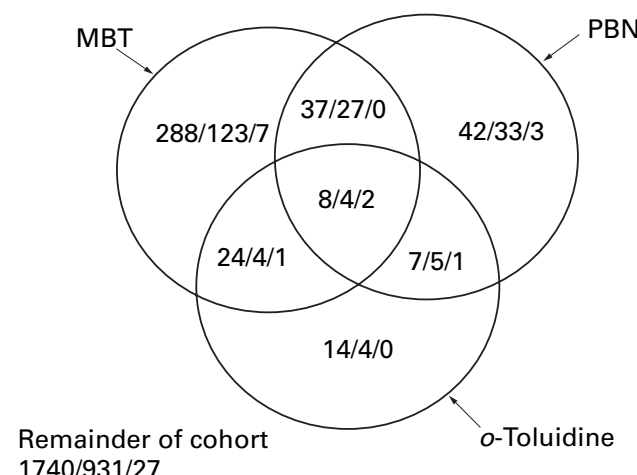

$1740 / 931 / 27$

Membership of MBT, PBN, and o-toluidine subcohorts.

Values a/b/c refer to (a) number of study subjects in subcohort, (b) number of deaths from all causes, (c) number of study subjects notified with bladder cancer (malignant or benign) on the basis of death certificates or cancer

registration particulars.

type of cohort (year of hire), employment status (still employed or left employment) and calendar period was also carried out (see table 3 for levels). Findings were little changed (not shown in table 9).

A further 11 cases of bladder cancer were available for analysis if non-malignant bladder tumours are also considered and table 10 provides relative risks of all notifications of bladder neoplasms by levels of the four variables of interest. The format of table 10 follows the display adopted in table 9. The larger number of cases provides more scope for a useful consideration of latency and all employment histories are lagged by 15 years - that is, for each period of follow up, employment history in the most recent 15 years is ignored. Significant positive trends (both monotonic) were found for the $\mathrm{PBN}$ and $o$-toluidine variables when exposures were analysed separately. All point estimates of risk were somewhat reduced when the four exposures were analysed simultaneously, and the trends for the $\mathrm{PBN}$ and $o$-toluidine variables, although still monotonic, were no longer significant. Additional adjustment for the variables already described had very little influence on these findings. The overlapping membership of three of the exposed subcohorts is shown in the figure.

\section{Discussion}

NEW FINDINGS

The overall mortality experience and the overall cancer experience of the total cohort were very similar to those of the general population of England and Wales. Given the many cause specific comparisons with national data which were carried out, the number of significant associations was modest (fewer than would be expected by chance alone). For almost all sites of cancer, neither the mortality data nor the cancer registration data for the exposed subcohorts give any cause for concern. There is no convincing evidence that occupational chemical exposures can influence the risks of cancer of the large intestine, ${ }^{8}$ and the excess mortality for this disease in the subcohort exposed to MBT may well be a chance finding or represent the effects of non-occupational factors. 
The findings for cancer of the bladder, however, need to be given close attention because obtaining information on bladder cancer in this workforce was one of the principal reasons for carrying out this study. Although the number of bladder cancers available for analysis in the total cohort is reasonable for performing a statistical analysis, only a few cases are available for analysis in the exposed subcohorts. Given the considerable overlap of membership of these subcohorts, confident interpretation of the findings will be difficult because transferring one or two cases from the current exposure categories to other exposure categories could have a considerable influence on the study findings.

The simplest interpretation of the bladder cancer findings from this survey may be that PBN (or a chemical reagent or chemical intermediate associated with the production of PBN at this factory in the 1930s and 1940s) is a bladder carcinogen. In the manufacture of $\mathrm{PBN}$, the reactor mass was sampled intermittently to determine the crystallisation point as an indication of the completion of the reaction. It is known that $\beta$-naphthylamine existed in the reactor mass at up to about $1200 \mathrm{mg} / \mathrm{kg}$ at some stages, but only a very few lead operators would have undertaken the sampling and it is not known whether or not any of the study subjects with bladder cancer from the subcohort exposed to PBN carried out such work. The limited positive findings found for the other three chemical exposures considered in the report (particularly MBT and aniline) may represent no more than the combined effects of chance and confounding from exposure to $\mathrm{PBN}$. If another bladder carcinogen has been present at the factory, then $o$-toluidine seems a more likely candidate than MBT, albeit the findings for $o$-toluidine are based on very small numbers. All these possible interpretations need, however, to be treated with caution. The new epidemiological evidence is limited in that, as already stated, the exposed subcohorts are modest in size. Also, the variables used as estimates or surrogates of cumulative exposures may well involve considerable misclassification. It was necessary to introduce several untested assumptions into the MBT exposure assessments to make them suitable for this analysis and the three other exposure variables were limited to duration of employment which will undoubtedly ignore important information.

Cigarette smoking is known to be an important cause of bladder cancer in the United Kingdom. ${ }^{9}$ Unfortunately, data on smoking were not available for study subjects. There is, however, no reason to think that age specific prevalence of smoking would be correlated with age specific cumulative exposures to the chemicals under study, and the low mortalities for lung cancer in the exposed subcohorts encourages us to think that smoking is not an important confounding factor in this study.

METHODOLOGICAL CONSIDERATIONS

An unusual feature of these analyses was allowing, in some calculations, cancer occurrences to be notified either by death certificates or by cancer registrations. Ideally, we would like details of all occurrences of cancer and their times of occurrence (dates of clinical manifestation) to be supplied in a uniform manner. Cancer registration schemes should take us much closer to this ideal than would the use of death certificate data alone. However, practical issues intercede: the registration of cancers in the United Kingdom is not compulsory; clinicians and histologists may hold views about the same clinical materials which differ from those of their colleagues; there are differences in the resources devoted by the regional cancer registries in recording all new cases of cancer and in removing duplicate registrations; registrations may not be accepted by the national cancer registration system if certain items of information are either missing or inconsistent with other items of information; diagnoses in patients treated privately may not be registered, patients present to their doctors with varying durations of symptoms, etc. It was clear from a general comparison of the death certificates and cancer registration particulars relating to this study that not all occurrences of cancer were being supplied by the national cancer registration scheme. The use of information from both sources enables us to get closer to the ideal of using information on all occurrences of cancer, thus increasing the statistical power of the analysis. There is a disadvantage to this combination procedure, however, and this arises from the fact that study subjects whose disease is notified by cancer registration particulars will be removed from the at risk population earlier than similar subjects whose disease is notified by death certificate only. This seems a relatively minor disadvantage. Furthermore, the adjustment for period by calendar year, a variable which had been categorised to separate periods without cancer registration details from those which had such details, indicated that this disadvantage was not having an effect of any practical importance on the study findings. What is important is whether the analysis provides a fair test of a useful null hypothesis; the null hypothesis in these "combination" analyses is that notification of bladder cancer is unrelated to histories of chemical exposure.

\section{TOXICOLOGICAL AND OTHER EPIDEMIOLOGICAL} DATA

Phenyl- $\beta$-naphthylamine comes under suspicion because of its relation to the well known potent bladder carcinogen $\beta$-naphthylamine. In 1987, PBN was evaluated by the International Agency for Research on Cancer (IARC) and it was concluded that the epidemiological evidence for carcinogenicity was inadequate and the animal evidence was limited. ${ }^{8}$ A dietary study in rats and mice involved daily doses of about $250 \mathrm{mg} / \mathrm{kg}$ bw/day and $1000 \mathrm{mg} / \mathrm{kg}$ bw/day in rats and mice respectively ${ }^{10}$; this was a maximum tolerated dose. A gavage study in Sprague-Dawley rats in which $600 \mathrm{mg} / \mathrm{kg}$ bw was administered twice a week was reported to be at the maximum tolerated dose, although there was no weight loss or other clinical indications of 
this. ${ }^{11}$ A similar study had previously been undertaken in golden hamsters. ${ }^{12}$ There was no evidence of carcinogenicity in any of these three studies. In the rat gavage study, Ketkar and Mohr reported that two of 40 males and one of 40 females had bladder papillomas whereas 40 male control animals had one bladder papilloma and one carcinoma. Inhalation of PBN aerosol produced lung cancers in mice. ${ }^{13}$ Other carcinogenicity studies were unconventional and involved subcutaneous administration to mice. Although tumours were produced, these studies were considered to provide only limited evidence of carcinogenicity. ${ }^{8}$ Mutagenicity studies with PBN are generally negative. ${ }^{8}$

Phenyl- $\beta$-naphthylamine has been reported to be metabolised in vivo to $\beta$-naphthylamine. ${ }^{14} 15$ The in vitro hepatic microsomal metabolism of PBN was studied in seven mammalian species. ${ }^{16}$ Although the formation of $\beta$-naphthylamine could not be shown in this preparation, 6- and 4'-hydroxylation occurred at differing rates (hamster:mouse:rat:human = $3.5: 1.9: 1.3: 0.6)$. If metabolism by hydroxylation provides some protection against metabolism by dephenylation, then the formation of $\beta$-naphthylamine might be higher in humans than in rats, mice, or hamsters. Although there is a credible mechanism by which PBN might be responsible for occupational bladder cancer, epidemiological studies on the effect of PBN alone are not available.

Ward et al reported an increase in the incidence of bladder cancer in a cohort of workers exposed to aniline and $o$-toluidine. ${ }^{17}$ Since this publication there has been considerable discussion in the scientific literature about the cause of this excess. ${ }^{18-21}$ It seems that there is general agreement that aniline on its own is not carcinogenic for humans and mice $^{22} 23$ despite the induction of various sarcomas when administered in the diet to Fischer 344 rats. ${ }^{23}$ The National Cancer Institute (NCI) bioassay with $o$-toluidine hydrochloride resulted in transitional cell carcinomas in female rats and sarcomas in both sexes of rats and mice; the conclusion was that the assay was positive in both rats and mice. ${ }^{24}$ The IARC concluded that there was sufficient evidence for carcinogenicity of $o$-toluidine in experimental animals and that $o$-toluidine should be regarded, for practical purposes, as if it presented a carcinogenic risk to humans. ${ }^{22}$ Sellers and Markowitz conclude that $o$-toluidine is a cause of human bladder cancer. ${ }^{25}$ The United Kingdom Health and Safety Executive set a maximum exposure limit (MEL) for $o$-toluidine on the basis of its carcinogenicity and its genotoxicity in vitro. ${ }^{26}$ The American Conference of Governmental Industrial Hygienists classify $o$-toluidine as an A2 suspected human carcinogen ${ }^{27}$ and the German MAK Kommission also classify it as carcinogenic. ${ }^{28}$ Although the evidence is not as conclusive as this level of agreement might suggest, the balance of probabilities is that $o$-toluidine has the capacity to induce human bladder cancer.

The toxicological evidence on the possible carcinogenicity of MBT relates to a single bioassay ${ }^{29}$ which produced results which, in our view, are uninterpretable. Tumours occurred, but the mortality was generally high and tumour incidences were often not dose related. The NCI conclusion was that there was some evidence of carcinogenic activity in rats, equivocal evidence in female mice, and no evidence in male mice. The German Advisory Committee on Existing Chemicals of Environmental Relevance (BUA) concludes on the basis of this study that the "possibility of MBT being carcinogenic cannot be ruled out." ${ }^{30}$ The only epidemiological evidence is the earlier report on this cohort,${ }^{1}$ from which no conclusion could be drawn, and the report from Nitro, West Virginia, which has insufficient power to come to any conclusion on the incidence of bladder cancer in workers who were not exposed to the potent carcinogen p-aminobiphenyl. ${ }^{2}$ In bacterial cell assays MBT is not mutagenic, but there is conflicting evidence of clastogenicity and mutagenicity in cultured mammalian cells.

\section{Conclusions}

It seems likely that some members of the exposed subcohorts have had occupational bladder cancer. From the point of view of identifying the causative agent, priority should be given to obtaining information on the cancer experience of other working populations exposed to PBN or $o$-toluidine, particularly as exposure to these compounds might now be (or become) common in developing and newly industrialised countries. A reliable scientific assessment of the carcinogenicity of MBT in humans is not possible; the evidence supplied by this study is of a limited nature and does not modify the BUA conclusion that the possibility of MBT being carcinogenic cannot be ruled out. Information from other populations will need to be made available; the earlier report from this study provides no independent information on this topic.

We thank the Office for National Statistics and the Department of Social Security for tracing the cohort, Mr David Williams for carrying out the exposure assessments, Dr Jesse Ellis for advice in interpreting the work histories, and Margaret Williams for word processing. We thank the factory management and workforce for allowing the study to be carried out.

1 Sorahan T, Pope D. Mortality study of workers employed at a plant manufacturing chemicals for the rubber industry: 1955-86. Br f Ind Med 1993;50:998-1002.

2 Strauss ME Barrick ED, Bannister RM. Mortality experience of employees exposed to 2-mercaptobenzothiazole at a chemical plant in Nitro, West Virginia. Br f Ind Med a chemical plant

3 Melick WF, Naryka JJ, Kelly RE. Bladder cancer due to exposure to $p$-aminobiphenyl: a 17 year follow up. $₹$ Urol 1971;106:220-6.

4 Coleman M, Douglas A, Hermon C, et al. Cohort study analysis with a Fortran computer program. Int $\mathcal{F}$ Epidemiol 1986;15:134-7.

5 EPICURE. Seattle: Hirosoft International Corporation, 1988. 6.

6 Breslow NE, Day NE. Statistical methods in cancer research. Volume II - The design and analysis of cohort studies. Lyon: IARC, 1987. (IARC Sci Publ No 82.)

7 Office of Population Censuses and Surveys. Area mortality tables. The registrar general's decennial supplement for England and Wales 1969-73. London: The Stationery Office, 1979. (Series DS no 3.)

8 International Agency for Research on Cancer. IARC monographs on the evaluation of carcinogenic risks to humans, suppl graphs on the evaluation of carcinogenic risks to humans, suppl
7 . An updating of IARC monographs volumes 1-42. Lyon: 7. An updating

9 Sorahan T, Lancashire RJ, Sole G. Urothelial cancer and Sorahan T, Lancashire RJ, Sole G. Urothelial cancer and
cigarette smoking: findings from a regional case-controlled study. Br $\mathcal{F}$ Urol 1994;74:753-6. 
10 National toxicology program. Technical report on the Toxicology and carcinogenesis studies of $N$-phenyl-2-naphthylamine (CAS No. 135-88-6) in F344/N rats and B6C3F mice (feed studies). Research Triangle Park, NC: 1987. (Tech Rep No 333; NIH Publ No 87-2589.)

11 Ketkar MB, Mohr U. The chronic effects of magenta, paramagenta and phenyl- $\beta$-naphthylamine in rats after intragastric ingestion. Cancer Lett 1982;16:203-6.

12 Green U, Holste J, Spikermann AR. A comparative study of the chronic effects of magenta, paramagenta, and phenyl- $\beta$ naphthylamine in Syrian golden hamsters. $\mathcal{F}$ Cancer Res Clin Oncol 1979;95:51-5.

13 You X, Yao Y. Experimental study of inhalation carcinogenesis of N-phenyl-2-naphthylamine aerosol on mice. (In Chinese.) Acta Biologica Experimentia Sinica 1981;14:13943.

14 Kummer R, Tordoir WF. Phenylbetanaphthylamine (PBNA), another carcinogenic agent? Tijdschrift voor

15 Laham S, Potvin M. Biological conversion of N-phenyl-2naphthylamine to 2-naphthylamine in the Sprague-Dawley rat. Drug Chem Toxicol 1983;6:295-309.

16 Anderson MM, Mitchum RK, Baland FA. Hepatic microsomal metabolism and macromolecular binding of the antioxidant N-phenyl-2-naphthylamine. Xenobiotica 1982;12:31-43

17 Ward E, Carpenter A, Markowitz S, et al. Excess number of bladder cancers in workers exposed to $o$-toluidine and aniline. F Natl Cancer Inst 1991;83:501-6.

18 Acquavella JF, Wilson JD, Conner P, et al. An alternative hypothesis for bladder cancer among workers exposed to $o$-toluidine and aniline. $\mathcal{F}$ Natl Cancer Inst 1991;83:1686.

19 Ward EM, Roberts D, Streicher R, et al. An alternative hypothesis for bladder cancer among workers exposed to $o$-toluidine and aniline: response. F Natl Cancer Inst 1991;83:1686-7.

20 Freudenthal RI, Anderson DP. A re-examination of the cause of excess bladder cancers in chemical plant workers. f Natl Cancer Inst 1994;86:60.
21 Ward EM, Roberts D, Dankovic D, et al. A re-examination of the cause of excess bladder cancers in chemical plant workers: response. $\mathcal{F}$ Natl Cancer Inst 1994;86:60-2.

22 International Agency for Research on Cancer. IARC monographs on the evaluation of carcinogenic risks to humans. Vol 27. Some aromatic amines and nitroso compounds, and inorganic fluorides used in drinking water and dental preparations. Lyon: IARC, 1982.

23 National Cancer Institute. Bioassay of aniline hydrochloride for possible carcinogenicity. Washington, DC: US Government Printing Office, 1978. (DHEW Publ No NIH 78-1385.)

24 National Cancer Institute. Bioassay of o-toluidine hydrochloride for possible carcinogenicity. Washington, DC: US, Government Printing Office, 1979. (DHEW Publ No NIH 79-1709.)

25 Sellers C, Markowitz S. Re-evaluating the carcinogenicity of -toluidine: a new conclusion and its implications. Regul Toxicol Pharmacol 1992;16:301-17.

26 Health and Safety Executive. Criteria document for an occupational exposure limit: o-toluidine. Sudbury, Suffolk: HSE Books, 1996.

27 American Conference of Governmental Industrial Hygienists (ACGIH). Documentation of the threshold limit values and biological exposure indices, 6th ed. Cincinatti: ACGIH, 1991: 1590-4.

28 Deutsche Forschungsgemeinschaft (DFG). MAK- und $B A T$-Werte-Liste. Weinheim, Germany: VCH Verslagsgesellschaft mbH, 1996:94;109, 130.

29 National toxicology program. Toxicology and carcinogenesis studies of 2-mercaptobenzothiazole (CAS No 149-30-4) in F344/N rats and B6C3F, mice. Draft report NTPTR 332. NC, USA: National Institute of Health, 1987. (NIH Publ No 87-2588.)

30 Gesellschaft Deutscher Chemiker (GDCh). Advisory Committee on Existing Chemicals of Environmental Relevance (BUA). 2-Mercaptobenzothiazole. Stuttgart, Germany: S-Hirzel-Verlag, 1997. 